\title{
Interfaces entre funções executivas, linguagem e intencionalidade ${ }^{1}$
}

\author{
Lauren Tonietto ${ }^{2}$ \\ Gabriela Peretti Wagner \\ Clarissa Marceli Trentini \\ Tania Mara Sperb \\ Maria Alice de Mattos Pimenta Parente \\ Universidade Federal do Rio Grande do Sul, Porto Alegre-RS, Brasil
}

\begin{abstract}
Resumo: A relação entre linguagem e funções executivas, também conhecidas como funções cognitivas complexas, já foi estabelecida no passado por Luria e Vygotsky. Este artigo tem por objetivo revisar o conceito de funções executivas sob as perspectivas neuropsicológica e cognitiva. Alguns dos reconhecidos modelos sobre processamento das funções executivas são apresentados, assim como estudos recentes sobre funções executivas em crianças. O desenvolvimento das funções executivas é discutido sob o ponto de vista biológico, neuropsicológico e cognitivo, destacando-se a importância da linguagem nesses processos, enquanto função reguladora da ação intencional. Essa discussão propõe que aspectos do desenvolvimento sejam incluídos nos modelos futuros sobre funções executivas.
\end{abstract}

Palavras-chave: linguagem, intencionalidade, lobo frontal, desenvolvimento.

\section{Interfaces among executive functions, language and intentionality}

\begin{abstract}
The relation between language and executive functions, also known as complex cognitive functions, has already been established in the past by Luria and Vygotsky. This article revises the concept of executive functions from a neuropsychological and cognitive perspective. Some of the executive function recognized models, as well as studies about executive functions in children, are presented. The development of executive functions is discussed from a biological, neuropsychological and cognitive perspective. The importance of language in these processes, as a regulative function of intentional action, is emphasized. This discussion proposes that developmental aspects should be included in models about executive functions.
\end{abstract}

Keywords: language, intentionality, frontal lobe, development.

\section{Interfaz entre funciones ejecutivas, lenguaje e internacionalidad}

Resumen: La relación entre lenguaje y funciones ejecutivas, también conocidas como funciones cognitivas complejas, fue establecida en el pasado por Luria y Vygotsky. Este artículo revisa el concepto de funciones ejecutivas bajo las perspectivas neuropsicológica y cognitiva. Se presentan algunos modelos sobre el proceso de las funciones ejecutivas, así como estudios sobre funciones ejecutivas en niños. Se discute el desarrollo de las funciones ejecutivas bajo una optica biológica, neuropsicologica y cognitiva, destacándose la importancia del lenguaje en esos procesos, como función reguladora de la acción intencional. Esta discusión propone que se incluyan aspectos del desarrollo en los modelos sobre funciones ejecutivas.

Palabras clave: lenguaje, intencionalidad, lóbulo frontal, desarrollo.

O termo Funções Executivas (FEs) representa um conjunto de processos cognitivos que envolvem capacidades de planejamento, execução de atividades complexas e outros processos que permitem que o indivíduo organize e estruture seu ambiente (Foster, Black, Buck, \& Bronskill, 1997), de acordo com um objetivo. A linguagem foi apontada como um componente relacionado a essas funções, primeiramente por Luria (1966) e, posteriormente, por Vygotsky (1998a, 1998b), e esta atuação é mantida em alguns modelos atuais de FEs (Baddeley, 2007; Fuster, 1997, 2004).

\footnotetext{
${ }^{1}$ Este texto foi revisado seguindo o Acordo Ortográfico da Língua Portuguesa (1990), em vigor a partir de $1^{\circ}$ de janeiro de 2009. A primeira e a segunda autora agradecem à CAPES (Coordenação de Aperfeiçoamento de Pessoal de Ensino Superior) pelo fomento à pesquisa (Bolsas de Doutorado).

${ }^{2}$ Endereço para correspondência

Lauren Tonietto. Rua Vasco da Gama, 283/603. CEP 92.310-340. CanoasRS, Brasil.E-mail: 1tonietto@ig.com.br
}

Este trabalho tem por objetivo aprofundar a análise da relação entre FEs e linguagem, mostrando que, à luz de teorias recentes de linguagem, esta relação deve ser valorizada quando se considera o aspecto da intencionalidade tanto nas FEs como na linguagem. Não há consenso entre as diversas acepções dos termos "intencionalidade" e "intenção", nas diferentes abordagens teóricas, já que os termos são muito complexos e de difícil tratamento conceitual. Conforme definição de Searle (1983), a "intencionalidade" é a capacidade de referir, direcionar ou significar algo a alguém. O presente artigo emprega uma visão sócio-histórica dos termos. "Intencionalidade" tem uma extensão mais ampla, ficando relacionada ao que é voluntário, à pretensão e ao planejamento, ou seja, a processos que envolvem pensamento. Conforme Tomasello (2005), a "intencionalidade" está relacionada às habilidades de intention-reading (leitura das intenções do interlocutor e reconhecimento das próprias intenções). O termo "intenção" está relacionado à ação ou ao comportamento, principalmente vinculado às primeiras ações intencionais 
da criança (Luria, 1966; Vygotsky, 1998a, 1998b). O termo "intencional" é utilizado em alguns trechos deste artigo como um qualificador ou adjetivo da ação, do comportamento ou, ainda, da comunicação (Tomasello, 2005; Vygotsky, 1998a, 1998b).

Na primeira parte do trabalho, os modelos de FEs que apontam para a participação da linguagem serão descritos, seguidos por um levantamento de pesquisas sobre o desenvolvimento das FEs. A seguir, serão apresentados os modelos sobre desenvolvimento de linguagem, enfatizando aqueles que valorizam a intencionalidade. Serão salientados os trabalhos de Carpenter, Nagell e Tomasello (1998) e Tomasello (2005) que relacionaram a intencionalidade como um componente essencial para o surgimento da linguagem, já que a necessidade de comunicação implica, desde a fase pré-linguística, uma intenção comunicativa, e os trabalhos de Luria (1966) sobre a relação entre linguagem e ações dirigidas a objetivos. Como conclusão, esta análise proporá que a intencionalidade possa ser um eixo comum, responsável pela interação entre o desenvolvimento da linguagem e o desenvolvimento das funções executivas.

\section{Modelos de Funções Executivas}

Como já apresentado, as FEs incluem atividades de seleção e estabelecimento de objetivos, planejamento, monitoramento e sequenciamento de ações (Foster e cols., 1997). As FEs articulam funções subordinadas, como raciocínio, memória de trabalho, planejamento, atenção e controle inibitório, entre outras, direcionando o comportamento no sentido de atingir seus objetivos (Stuss \& Levine, 2002).

As FEs dependem de um processamento complexo, envolvendo o lobo frontal, alguns núcleos da base (como o striatum), o tálamo, as estruturas límbicas e as vias que conectam essas regiões. Contudo, são as áreas pré-frontais que exercem um papel determinante sobre essas funções (Stuss \& Levine, 2002). Estas possuem regiões anatômicas e funcionais distintas (Cummings, 1995; Fuster, 1997), as quais refletem a complexidade dos processos envolvidos.

Existem diversos modelos teóricos sobre o processamento das funções executivas. Aliás, o conceito de funções executivas ainda carece de uma definição formal (Jurado \& Rosselli, 2007). Contudo, o que é aceito na literatura é o fato de se tratar de um modelo multiconceitual e multicomponencial (Stuss \& Levine, 2002). Para este trabalho, foram selecionados apenas três modelos, por relacionarem os processos executivos e linguísticos, para uma revisão mais ampla acerca de funções executivas, consultar Grafman (1995), Stuss e Benson (1986). Cada um destes modelos se relaciona às questões de linguagem e de intencionalidade de maneira distinta, porém, todos os aqui citados apontam para o papel dos processos executivos no gerenciamento do comportamento e/ou na ação dirigida a metas.

\section{Modelo dos Sistemas Funcionais}

Luria (1966, 1973a) foi um dos primeiros a pesquisar os processos executivos, embora não os tenha tratado com esse nome. Em seu modelo neurofisiológico, o sistema nervoso é composto de unidades anatômicas e funcionais que apresentam uma atuação hierárquica. A Unidade III, composta pelos lobos frontais, controla as demais áreas, exercendo funções de programação, regulação e verificação da atividade mental. Ela é responsável pela organização das intenções e planos para as ações humanas, bem como a regulação do comportamento e verificação da atividade consciente. Neste modelo, fica bastante evidente a importância do planejamento e do comportamento dirigido a objetivos para a execução de funções complexas. Apesar de não utilizar o termo intencionalidade, esta está vinculada ao conceito de ações dirigidas a objetivos.

Segundo Luria (1966), todos os processos mentais conscientes que governam as ações humanas envolvem a participação do sistema de comunicação verbal e estão, de fato, sob seu domínio. Portanto, os processos mentais (o que inclui as funções executivas) são guiados pela linguagem. No que se refere às relações entre linguagem e funções executivas, a partir de observações de pacientes lesados frontais, Luria (1973b) descreve as interfaces entre os sistemas verbal e executivo. Por exemplo, um paciente com lesão pré-frontal pode facilmente repetir uma instrução verbal dada pelo experimentador. Esse paciente consegue memorizar a instrução e repeti-la após vários dias. Contudo, o indivíduo tende a apresentar problemas quando tiver de executar uma ação (uma sequência determinada de movimentos com os dedos, por exemplo) por si mesmo, outrora descrita verbalmente. Ele pode até obter sucesso na primeira tentativa, mas tende a falhar nas subsequentes. Entretanto, ao reproduzir a instrução verbalmente, esse paciente tende a executar a ação corretamente. Com base nessas observações, Luria (1966) afirmou que existe uma importante interação entre os sistemas funcionais linguístico e executivo. Pacientes com lesões pré-frontais, em geral, tendem a apresentar linguagem preservada, mas podem apresentar uma inabilidade para executar ações na ausência de autoinstrução verbal.

\section{Modelo de Memória de Trabalho}

Recentemente, a relação entre linguagem e FEs tem sido valorizada pelo modelo de Memória de Trabalho (MT), conceito criado por Baddeley e Hitch (1974). Essencialmente, a função da MT é auxiliar a atenção seletiva e favorecer a representação mental da informação a ser processada na ausência de inputs perceptuais. $\mathrm{O}$ armazenamento da informação na MT é temporário, porém dura o tempo suficiente para que seja manipulada e para que ocorra o processamento cognitivo durante a execução de tarefas (Baddeley, 2007).

Apesar de ser um modelo de memória, envolve funções executivas por meio de um de seus principais componentes, o executivo central. Este, responsável por gerenciar as interações entre os subsistemas da MT e a Memória de Longo Prazo (MLP), tem uma função complexa que inclui análise das informações oriundas de inputs sensoriais, seleção daquelas relevantes, filtragem, para que possam ser armazenadas na 
MLP, e recuperação das informações da MLP, conforme a necessidade (Baddeley \& Hitch, 1974; Baddeley, 2007).

$\mathrm{O}$ executivo central relaciona-se com a linguagem por meio da alça fonológica. Esta é ativada sempre que há demanda auditiva (como na fala, por exemplo). Já o bloco visuoespacial é necessário para o processamento de informações visuais (figuras, localização de objetos) (Baddeley \& Hitch, 1974; Baddeley, 2007).

Esse modelo contempla aspectos linguísticos, uma vez que inclui componentes de processamento de informações fonológicas ou auditivas (alça fonológica) e também o componente gráfico/pictórico da linguagem (bloco visuoespacial). Em outras palavras, a alça fonológica permite um armazenamento temporário dos sons da linguagem enquanto uma tarefa cognitiva está sendo desenvolvida. Já o bloco visuoespacial exerce um papel na manutenção temporária das letras do alfabeto e de outros símbolos no sistema cognitivo. Mesmo figuras, por exemplo, contêm aspectos linguísticos, uma vez que representações semânticas estão associadas a componentes gráficos. Portanto, durante uma dada tarefa, as informações fonológicas são conectadas às visuais, fornecendo-lhes significado (Baddeley \& Hitch, 1974; Baddeley, 2007). Além disso, numa versão posterior à da década de 1970 (Baddeley \& Hitch, 1974), uma alça episódica também desempenha um papel em processos linguísticos, uma vez que conecta os dados fonológicos e visuoespaciais (armazenados na MLP), especialmente, ao componente semântico da mesma (para uma revisão, consultar Baddeley, 2007).

Entretanto, apesar de salientar a importância dos processos linguísticos de origem fonológica para a MT, esse modelo não considera a característica comunicativa da linguagem nem sua intencionalidade. É curioso observar uma oposição entre os dois modelos já descritos: para Luria, a linguagem reorganiza a ação, enquanto para Baddeley, a linguagem está subjacente ao executivo central (com processos atencionais não linguísticos), o qual assume o papel gerenciador do sistema linguístico, basicamente fonológico.

\section{Modelo de Organização Temporal do Comportamento}

Fuster (1997) elaborou um modelo de FEs com base nitidamente anatomofisiológica. Para o autor, o lobo frontal divide-se em áreas motoras e não motoras, as primeiras efetoras (não cognitivas propriamente ditas), as últimas, regiões implicadas no processamento cognitivo. Estas áreas, conhecidas como pré-frontais, são subdivididas em três porções anatomofuncionais distintas: dorsolateral, ventromedial e orbitofrontal. A região dorsolateral está envolvida em processos "racionais", responsável pela mediação de funções de resolução de problemas, abstração, memória de trabalho e raciocínio, entre outras. As áreas ventromediais e orbitofrontais apresentam funções "límbicas" ou subjetivas: as porções ventromediais estão relacionadas à iniciativa e à motivação, enquanto as orbitofrontais estão envolvidas no comportamento emocional e na estrutura de personalidade.

Alguns anos mais tarde, o autor publicou estudos relativos a um avanço de seu modelo, o ciclo percepção-ação (Fuster, 2004). Este é necessário para que o comportamento dirigido a metas ocorra, ou seja, é por meio dele que ocorre a transferência da informação do passado para o futuro e da percepção para a ação. $O$ ciclo percepção-ação é um circuito envolvendo a integração do indivíduo com o ambiente. As áreas anteriores e posteriores do encéfalo se comunicam para tal, mas também trocam informações dentro de si mesmas. Portanto, o fluxo de informação é bidirecional em cada uma das sub-regiões, bem como há comunicação das mesmas com as demais áreas corticais (Fuster, 2004). Em se tratando de processos executivos, o córtex pré-frontal recebe informações perceptuais oriundas de áreas posteriores do encéfalo e utiliza esses dados no planejamento e na execução de uma determinada ação em resposta aos inputs sensoriais - ação essa que pode assumir a forma de resposta motora ou linguagem (Fuster, 2004).

Contudo, o modelo não explica como os processos linguísticos se desenvolvem e em que medida estão relacionados a intenções e planos. Ao contrário, a linguagem é vista como um output para o mundo exterior. Entretanto, as etapas de processamento nesse modelo (de áreas posteriores para anteriores do encéfalo) são similares às citadas por Luria (1973a), quando o mesmo menciona as unidades e zonas corticais, bem como as leis de processamento das funções cognitivas. No que tange à intencionalidade, apesar de não utilizar esse conceito, o autor (Fuster, 1997, 2004) relaciona as regiões mesiais dos lobos frontais ao comportamento dirigido a objetivos. Tal associação é possível em função de estudos com pacientes lesados cerebrais - observou-se que pacientes com lesões mais mesiais no córtex pré-frontal, especialmente próximas ao cíngulo, tendem a mostrar sintomas de apatia e abulia (Fuster, 1997).

Em suma, os três modelos teóricos sobre o processamento das FEs descritos anteriormente propõem diferentes relações entre as mesmas. O modelo dos Sistemas Funcionais de Luria (1966, 1973a) destaca a função da Unidade III no controle das intenções e no planejamento das ações, por sua vez, controlada pela linguagem. É valorizada a função de autorregulação e de metacognição. Já para o modelo de Memória de Trabalho (Baddeley \& Hitch, 1974; Baddeley, 2007), a linguagem é focalizada apenas em seu sistema fonológico e é subordinada a um controle executivo de origem atencional. Por fim, apesar de o modelo de Organização Temporal do Comportamento (Fuster, 1997, 2002, 2004) valorizar a ação voltada para objetivos e ser dependente da subjetividade, a linguagem é apenas uma das ações de seu output.

Embora as FEs tenham seu ápice na fase adulta, sua emergência ocorre ainda na infância, momento em que a linguagem também desempenha um papel fundamental. Por isso, o próximo tópico deste artigo discute alguns aspectos, inicialmente aspectos biológicos e maturacionais e, em seguida, estudos sobre FE ao longo do desenvolvimento. 


\section{Desenvolvimento das FEs e da linguagem}

\section{Aspectos biológicos e maturacionais}

Durante o desenvolvimento, as funções executivas e a linguagem parecem interagir, já que o surgimento da intencionalidade inerente ao desenvolvimento da linguagem (Carpenter e cols., 1998; Tomasello, 2005) também parece necessário para a definição de metas e planos, característica das funções executivas. Neste tópico serão revisados alguns indicativos biológicos de desenvolvimento cortical, os quais supostamente justificariam a emergência dos primórdios das funções executivas e da linguagem em uma etapa inicial do desenvolvimento. Supõe-se que algum grau de maturação cortical seja necessário para que as diferentes funções cognitivas possam se desenvolver. Essa interação entre os aspectos biológicos e histórico-culturais no desenvolvimento já havia sido destacada por Vygotsky (1998a, 1998b).

Fuster (2002) afirma que a substância cinzenta préfrontal aumenta em volume após o nascimento, chegando ao ápice entre os quatro e 12 anos de idade, e reduz gradualmente a partir da idade adulta. Em relação à substância branca, a mielinização dos axônios com conexão frontal está entre os fatores que permitem o desenvolvimento cognitivo infantil, ou seja, a maturação cognitiva durante a infância está diretamente relacionada à mielinização (Huttenlocher, 1990). Sabe-se que a mielina tem como principal função a aceleração da velocidade do impulso nervoso, o que favorece a rapidez do processamento de informações, fundamental para o processamento cognitivo. Outros fatores relacionados à maturação cortical, além da mielinização, incluem o prolongamento dos axônios e a arborização dendrítica, o que permite o intercâmbio de informações. Por meio do aprimoramento cortical é possível a maturação intelectual e, consequentemente, a emergência de processos como a atenção, a criatividade e a linguagem, as quais fornecerão subsídios para organizar o comportamento e a cognição e permitir ações dirigidas a objetivos (Fuster, 2002).

Um estudo medindo a atividade metabólica cerebral de crianças, por meio da tomografia por emissão de pósitrons, indicou uma atividade subcortical mais intensa do que a atividade cortical até a idade de três meses (Schonen, Van Hout, Mancini, \& Livet, 1998). A partir daí, as atividades occipital, temporal e parietal também aumentam. Ao redor dos nove ou dez meses de idade, a atividade frontal cresce. E, finalmente, em torno dos quatro anos, a atividade metabólica cortical apresenta um pico (Schonen e cols., 1998). Esses dados revelam certa lógica do ponto de vista do desenvolvimento, já que, até os três meses de idade, o bebê parece estar mais envolvido com atividades mais motoras e internas, tais como a alimentação (mamadas) e o controle do sono, funções relacionadas às áreas subcorticais. Também parece lógica a atividade cortical crescente em torno dos nove ou dez meses, idade em que, do ponto de vista cognitivo, como veremos adiante, surgem os primórdios da atenção compartilhada, atividade importante para a regulação do comportamento. Da mesma forma, a idade de quatro anos, quando também foi encontrado um pico na atividade metabólica cortical, cognitivamente representa um marco no desenvolvimento por indicar o início das habilidades relacionadas à compreensão dos pensamentos e sentimentos dos outros, conhecidas como "teoria da mente", também discutidas no próximo tópico.

Tais achados também vão ao encontro do que Luria (1966, 1973a) afirmou acerca de uma das leis que regem as funções corticais, a saber, a lei da estrutura hierárquica das zonas corticais, segundo a qual há uma interação contínua entre as unidades. Sabe-se que a atividade metabólica está relacionada à ativação de funções desempenhadas pelas áreas cerebrais correspondentes. Assim, uma maior atividade de áreas corticais indica a ativação de funções relacionadas ao controle executivo e aos demais processos cognitivos.

Os dados neurobiológicos do desenvolvimento infantil inicial levam, portanto, a concluir que há uma maturação biológica necessária ao desenvolvimento cognitivo. Determinadas estruturas corticais precisam atingir um razoável nível de desenvolvimento para que possam operar processos cognitivos tais como atenção e memória e, posteriormente, ações mais complexas como linguagem, planejamento e execução de atividades. Recentemente, diferentes estudos têm buscado investigar esses processos em crianças de diferentes idades, buscando identificar como emergem as funções executivas e quais as causas das disfunções executivas encontradas nas diferentes patologias.

\section{Estudos sobre FEs e o desenvolvimento}

Na idade adulta, observa-se que uma lesão cerebral pode ocasionar o que é chamado em neuropsicologia de dissociação dupla: pacientes com lesão pré-frontal apresentam falhas executivas sem grandes problemas de linguagem (Bechara, Damasio, Damasio, \& Anderson, 1994), enquanto pacientes com lesões mais posteriores, principalmente no hemisfério esquerdo, apresentam o quadro inverso: falhas de linguagem sem dificuldades executivas (Schonen e cols., 1998). Tais dissociações duplas, para a Neuropsicologia Cognitiva, significam a presença de funções independentes (Caramazza \& McCloskey, 1988). Entretanto, a análise mais minuciosa das ações desses pacientes revelou a existência de uma interação entre a habilidade linguística e a organização executiva, a primeira favorecendo o desempenho da segunda.

$\mathrm{O}$ estudo da interdependência entre funções no desenvolvimento pode ser muito esclarecedor, uma vez que a cognição está em formação. Entretanto, além de recentes e esparsos, a diversidade das habilidades cognitivas avaliadas no estudo da FE, durante o desenvolvimento, reforça a ausência de consenso conceitual entre os pesquisadores. $\mathrm{O}$ estudo da emergência e do desenvolvimento das FEs parece ainda mais complexo do que os estudos com adultos e idosos, uma vez que elas ainda não operam de forma completa. Já que funções como atenção, planejamento, memória e 
inibição ainda estão em desenvolvimento, uma variabilidade de tarefas e de funções é investigada sob o rótulo de FE, o que torna difícil a comparação e a obtenção de um modelo desenvolvimental.

A seguir, são discutidos alguns estudos considerados importantes para os objetivos do presente artigo pelo fato de apresentarem dados sobre o desenvolvimento das funções executivas no desenvolvimento típico, em situações de adversidades biológicas (lesões cerebrais e fenilcetonúria) e comportamentais (Transtorno de Asperger, Transtorno de Déficit de Atenção e Hiperatividade, Transtorno de Escrita e Leitura, desenvolvimento de teoria da mente e Autismo). É interessante destacar que não foram localizados estudos estabelecendo relações entre as FEs e a linguagem.

Zelazo, Craik e Booth (2004) destacam que, ao longo do desenvolvimento típico, as crianças gradualmente melhoram sua capacidade de representar múltiplos aspectos de um problema, planejar o curso futuro da ação, manter o plano em mente e agir sobre o mesmo, além de detectar e utilizar informações sobre erros. Segundo os autores, a crescente habilidade de se engajar em pensamentos e ações deliberadas dirigidas a um objetivo é frequentemente estudada sob a rubrica de funções executivas. Essas dependem de uma crescente efetividade de processos como atenção seletiva, memória de trabalho e controle inibitório. Esse estudo avaliou mudanças nas funções executivas durante o curso da vida, em crianças com média de idade de 8,8 anos, adultos e idosos, utilizando três tarefas: uma tarefa de completar palavras, a tarefa Visually Cued Color-Shape e a Auditorily Cued Number-Numeral. Os resultados mostraram que as crianças, assim como os idosos, tiveram mais erros perseverativos, um indício de disfunção executiva, quando comparados aos adultos jovens. Tais resultados geraram, conforme esperado, uma curva em "U" invertida, já observada em outros processos cognitivos básicos, tais como velocidade de processamento e memória de curto prazo. Os autores concluem que as funções executivas crescem e declinam no curso do desenvolvimento, principalmente a função do controle consciente neste processo, e, portanto, da linguagem. Supõe-se, entretanto, que as crianças têm mais dificuldade de utilizar a informação consciente para controlar seu comportamento, agindo, portanto, de forma mais automática.

A forma clássica de estudo de qualquer disfunção provavelmente seja a lesão cerebral, tal como realizado no estudo de Filley, Young, Reardon e Wilkening (1999). Participaram desse estudo 63 pacientes com lesões cerebrais de etiologias variadas e 48 pacientes com transtornos psiquiátricos diversos com idades entre oito e 17 anos. Todos foram detalhadamente testados com a Wechsler Intelligence Scale for Children (WISC-III) e o Wisconsin Card Sorting Test (WCST), além dos testes neuropsicológicos e de neuroimagem. Os resultados mostraram que as crianças com lesões nas regiões frontais dorsolaterais apresentaram maiores prejuízos no WCST, enquanto desempenhos comparáveis aos demais grupos foram obtidos no WISC-III. Os dados mostram o papel das regiões frontais dorsolaterais na mediação das funções executivas nas crianças e do Wisconsin como medida da integridade frontal dorsolateral.

O estudo de Malloy-Diniz e cols. (2004) avaliou funções executivas em crianças fenilcetonúricas em idade bastante precoce, entre nove e 12 meses de idade. Os autores consideram que as funções executivas compreendem habilidades necessárias para a solução de problemas como, por exemplo, o planejamento, a memória operacional e a inibição e autorregulação do comportamento. A pesquisa buscou generalizar os resultados obtidos por Diamond (1998) para crianças brasileiras. Participaram do estudo dois grupos de crianças, sendo um de 21 crianças fenilcetonúricas e outro de 18 crianças normais. Foram correlacionados os níveis de phe (aminoácido fenilalanina) com o desempenho na tarefa $\mathrm{AB}$, uma prova piagetiana que avalia a habilidade da criança de inibir uma ação habitual ou preponderante, relacionada ao desenvolvimento das funções executivas. A criança observa um objeto ser escondido debaixo de um anteparo A, por exemplo. Retira o anteparo A e alcança o objeto. Em seguida, o mesmo objeto é escondido debaixo de um anteparo B, colocado ao lado do anteparo A. Crianças entre oito e 12 meses de idade frequentemente cometem o erro $\mathrm{AB}$, ou seja, continuam buscando o objeto em $\mathrm{A}$, apesar de terem observado o objeto ser escondido em $\mathrm{B}$, sobretudo quando não podem buscar o objeto imediatamente após ele ter sido escondido. Os resultados confirmaram a hipótese de estudo, demonstrando que as crianças com níveis altos de phe apresentam dificuldades no desempenho de tarefas que dependem de funções executivas. Destaca-se que os déficits encontrados não são explicados pelo nível de desenvolvimento geral, já que os resultados da escala mental da Escala Bayley não revelaram diferença significativa entre os três grupos de crianças.

O estudo de Nydén, Gillberg, Hyelmquist e Heiman (1999) investigou déficits de atenção e função executiva em dez crianças com transtorno de Asperger, dez crianças com Transtorno de Déficit de Atenção e Hiperatividade (TDAH), dez crianças com transtorno de escrita e leitura e dez crianças com desenvolvimento típico de oito a 11 anos de idade, utilizando tarefas neuropsicológicas e cognitivas. $\mathrm{O}$ grupo com TDAH apresentou maiores dificuldades nas tarefas propostas, mostrando uma correlação entre esse transtorno e as FEs.

Os pesquisadores têm buscado estabelecer relações entre as FEs e a "teoria da mente", já que parece existir alguma semelhança entre o comportamento de sujeitos com disfunção executiva e com autismo. A "teoria da mente" implicaria uma habilidade bastante complexa de compreender o que pensam e sentem as outras pessoas. No autismo, existiria uma dificuldade no desenvolvimento desta habilidade. Essa dificuldade contribuiria para um comportamento social disfuncional. Uma revisão sobre o tema pode ser encontrada em Bosa (2001).

No estudo de Perner, Lang e Kloo (2002) com 82 crianças entre três e seis anos de idade, utilizaram-se a Tarefa de 
Crença Falsa, prova amplamente reconhecida para testar a aquisição da teoria da mente, e uma versão simplificada do WCST, classicamente utilizada para avaliar funções executivas. Os resultados mostraram uma forte correlação entre crença falsa e controle executivo, ou seja, crianças que obtiveram mais acertos em tarefas que indicam a capacidade de compreender o pensamento dos outros apresentaram melhor controle executivo. Entretanto, embora existam algumas hipóteses explicativas para a correlação encontrada, os autores destacam a dificuldade em estabelecer uma relação de causa e efeito para os dados, sugerindo que outros estudos relacionados ao desenvolvimento de tais habilidades devem buscar esclarecer a questão. Fica claro, contudo, que o controle inibitório não é o único ou o mais importante fator envolvido nas tarefas de teoria da mente. Por outro lado, o estudo de Baron-Cohen, Leslie e Frith (1985) demonstrou que um déficit cognitivo explicaria a dificuldade existente no autismo de compreender o pensamento e sentimento do outro e, a partir disso, predizer seu comportamento e regular o próprio comportamento.

O estudo de Filley e cols. (1999) mostrou a correlação de lesões com dificuldades executivas. Os estudos de Diamond (1998) e Malloy-Diniz e cols. (2004) mostraram que crianças com fenilcetonúria - com problemas em substâncias ativas no córtex frontal - tiveram prejuízo no controle inibitório da ação em comparação com crianças normais. Por outro lado, o estudo de Perner, Lang e Kloo (2002) e a revisão de Bosa (2001) apontam para uma correlação importante entre a dificuldade em compreender as intenções do interlocutor e as funções executivas. Pode-se pensar, portanto, que dificuldades no desenvolvimento da intencionalidade, que implica no reconhecimento das intenções do outro e das próprias (Carpenter e cols., 1998; Tomasello, 2005), podem estar subjacentes às disfunções executivas. Assim, esse levantamento dos poucos estudos sobre o desenvolvimento das FEs sugere que a interação com a linguagem esteja no plano dos aspectos linguísticos relacionados à intencionalidade.

\section{A intencionalidade nos modelos de aquisição da linguagem}

Diferentemente dos estudos desenvolvimentais das FEs, a aquisição da linguagem intriga pesquisadores há várias décadas. A linguagem foi estudada sob diferentes perspectivas teóricas, que serão brevemente discutidas neste tópico, enfatizando-se modelos recentes que valorizam a intenção na aquisição linguística.

$\mathrm{Na}$ perspectiva comportamentalista, a linguagem é considerada como um comportamento verbal. Assim, como qualquer outro comportamento, poderia ser aprendida por meio do contato social entre o organismo com seu ambiente (Skinner, 1957). Partindo de uma perspectiva oposta, Chomsky (1957) propôs a ideia de um módulo inato da linguagem que capacitaria o ser humano para o conhecimento de estruturas sintáticas subjacentes à língua. Essa ideia tem sido recentemente compartilhada por Pinker (1997) que propõe a existência de regras sintáticas inatas que permitem o reconhecimento e o aprendizado da língua.

Atualmente, a ideia que parece mais plausível é que a criança possui capacidades inatas que possibilitam o aprendizado da linguagem (Chomsky, Belletti, \& Rizzi, 2002), mas o conjunto de experiências modula a aquisição. Essa abordagem é conhecida como interacionista ou sociointeracionista, no sentido de que o desenvolvimento da linguagem ocorre a partir das interações propiciadas pelas relações sociais. Dentro dessa perspectiva, destaca-se a teoria de Piaget (1964/2003), segundo a qual a linguagem seria uma expressão da função simbólica subjacente, estreitamente relacionada ao pensamento. A linguagem e a função simbólica seriam, portanto, condições necessárias, mas não suficientes, para que o pensamento se torne possível (Piaget \& Inhelder, 1959/1975).

Outras teorias do desenvolvimento enfatizaram a importância da linguagem para o desenvolvimento cognitivo infantil (Luria, 1966; Vygotsky, 1998a, 1998b). Embora não tenham tratado de certas funções cognitivas sob a rubrica de "funções executivas", a leitura dessas teorias relaciona elementos da linguagem a funções e processos atualmente definidos como tal.

O primeiro pesquisador a destacar o papel da linguagem no desenvolvimento de funções relacionadas ao córtex pré-frontal, região destacadamente envolvida nas funções executivas, foi o neuropsicólogo A. R. Luria. Fundamentado principalmente nas ideias de L. S. Vygotsky, Luria (1966, 1970) destacou que as funções mentais superiores são consideradas como produtos complexos do desenvolvimento sociocultural. Este, por sua vez, exerce uma influência fundamental para o desenvolvimento da linguagem. Conforme ressaltaram Stuss e Benson (1984), Luria sugeriu que a fala interna tem um importante papel na programação e regulação do comportamento. A fala interna seria responsável pelas formas mais complexas de comportamento voluntário, selecionando as questões mais salientes, criando um plano interior e, assim, monitorando o desempenho por meio da comparação com a intenção original. Portanto, existiria uma associação fundamental entre linguagem e ação, sendo a ação voluntária controlada pelo pensamento verbal. Conforme destacado também por Frawley (2000), a linguagem tem uma função de controle na ação da criança.

Vygotsky (1998a) buscou compreender o processo por meio do qual a criança desenvolve as funções cognitivas, passando de funções elementares para funções complexas. Durante os primeiros estágios do desenvolvimento, as ações infantis apoiam-se no uso de sinais evocativos exteriores, denominados signos externos. Posteriormente, no curso do desenvolvimento, a criança passa por um processo de internalização, em que os signos externos são gradualmente substituídos por signos internos, gerando a base para a capacidade representacional. O processo de internalização ocorre somente quando a criança torna-se capaz de compreender 
que os signos externos são dotados de significado. Esta compreensão representa o salto fundamental para o simbolismo. Assim, a capacidade simbólica subjacente à linguagem ou sistema simbólico representaria uma função organizadora específica, produzindo novas formas de comportamento. Experimentos com crianças, descritos por Vygotsky (1998a), evidenciam que a "fala egocêntrica" apresentada pela criança, enquanto busca solucionar um problema, adquire o caráter de planejamento, visando a atingir um objetivo específico, função essencialmente executiva. Assim, a fala coordena o comportamento intencional da criança, ou seja, desempenha uma "função de planejadora". Segundo o autor,

a capacitação especificamente humana para a linguagem habilita as crianças a providenciarem instrumentos auxiliares na solução de tarefas difíceis, a superar a ação impulsiva, a planejar uma solução para um problema antes de sua execução e a controlar seu próprio comportamento (Vygotsky, 1998a, p. 38).

A linguagem possui, então, duas funções: uma comunicativa e outra relacionada à organização do pensamento e das ações. Posteriormente, a "fala egocêntrica" transformase em fala interna, forma tipicamente adulta da linguagem. A fala deixa de ser necessária à coordenação da ação, sendo substituída pelo diálogo interno, sendo este responsável pela organização do pensamento e planejamento e coordenação da ação.

Segundo Vygotsky (1998a), o desenvolvimento do sistema simbólico ou da linguagem representa a construção sobre a qual todas as demais funções cognitivas estão alicerçadas, tais como planejamento, raciocínio, memória, capacidade de avaliar opções e realizar escolhas, entre outras. As relações existentes entre as funções pensamento e linguagem foram mais detalhadamente descritas em outros trabalhos (Vygotsky, 1998b). Segundo essa perspectiva, pode-se concluir que prejuízos na capacidade simbólica necessária à linguagem gerariam dificuldades na coordenação da ação intencional.

Recentemente, dentro de uma perspectiva sociointeracionista da linguagem, Carpenter e cols. (1998) e Tomasello (2005) afirmam que a comunicação intencional está presente no desenvolvimento, antes do surgimento da linguagem falada ou da fase linguística do desenvolvimento da linguagem. Mesmo os comportamentos mais iniciais dos bebês são comunicativos no sentido de que os adultos são capazes de interpretá-los e de responder a esses apropriadamente. Por exemplo, o choro de um recém-nascido pode indicar à mãe que ele está com fome ou dor, ou o inclinar-se do bebê para um objeto pode indicar ao pai que ele deseja obter o referido objeto.

Segundo Carpenter e cols. (1998), muito antes das primeiras palavras, o bebê já se engaja em interações face a face com seu interlocutor, desenvolvendo sua capacidade atencional principalmente por meio da visão. Posteriormente, o bebê passa a alternar o olhar entre o interlocutor e o objeto da atenção de ambos, que pode ser um brinquedo, uma revista ou qualquer objeto que passa a ser o foco da atenção mútua.

Em torno dos nove meses, a criança já deve estar desenvolvendo a habilidade de compartilhar a atenção voltada a um objeto ou evento com outras pessoas, estabelecendo uma relação triádica, que é a base da atenção compartilhada. Nesse momento, surgem os gestos de apontar, por exemplo, que servem também para direcionar a atenção do interlocutor, um comportamento intencional. Assim, o comportamento intencionalmente comunicativo refere-se ao momento a partir do qual o bebê compreende que seus sinais são comunicativos, dirigidos a outras pessoas com uma intenção, e essas pessoas são percebidas como agentes comunicativos que percebem e respondem a esses sinais. A atenção compartilhada seria, assim, mais uma etapa do desenvolvimento que levará a criança a compreender o outro como um interlocutor com intenções, desejos e pontos de vista próprios. Essas seriam as bases da Teoria da Mente (Carpenter e cols., 1998; Tomasello, 2005).

\section{Relações entre intencionalidade, linguagem e funções executivas}

Ao demonstrar a importância da linguagem para o desenvolvimento, Carpenter e cols. (1998) e Tomasello (2005) enfatizam que a intencionalidade está presente desde a fase pré-linguística da linguagem, diferentemente de Vygotsky (1998a, 1998b) que destacou a importância da linguagem enquanto sistema simbólico. Pensando em termos de desenvolvimento, discutiu-se que o surgimento do comportamento intencional ocorre bastante precocemente, no final do primeiro ano de vida (Carpenter e cols., 1998; Tomasello, 2005). A partir desse momento, já é possível observar na criança, com desenvolvimento típico, o desejo de se comunicar e de ser como os outros. Para isso, a criança passa a chamar a atenção do interlocutor e a dirigi-la a seus objetivos, além de começar a guiar suas ações para o alcance de metas específicas.

Carpenter e cols. (1998) e Tomasello (2005) postulam que a ação intencional e dirigida a um objetivo somente tornase possível com o desenvolvimento da habilidade de atenção compartilhada. Esta habilidade é fundamental para o desenvolvimento sociocultural e dependente da motivação para a interação e do desejo de imitar os outros. Evidencia-se no brinquedo infantil, quando a interação com um objeto ou evento adquire sentido quando compartilhada com um interlocutor. A atenção compartilhada permitiria, então, o planejamento e coordenação da ação, dirigindo e regulando o comportamento infantil. Nesse contexto, a capacidade de compreender que $\mathrm{o}$ interlocutor tem intenções próprias, relacionada à teoria da mente, representa um componente essencial para a interação. Essa capacidade permite que a criança coordene suas ações baseada na compreensão das intenções dos outros.

Essa ideia parece ir ao encontro das ideias de Luria (1966), quando propôs que a linguagem teria uma função 
reguladora do comportamento dirigido a objetivos. O planejamento e as ações dirigidas a objetivos, uma das funções atribuídas ao conjunto das funções executivas, certamente estão ligados à intencionalidade (Carpenter e cols., 1998; Tomasello, 2005). Talvez seja plausível pensar que o conjunto de processos cognitivos envolvidos nas funções cognitivas seja dependente da intencionalidade tanto quanto a linguagem. Ou seja, para atingir um objetivo por meio de uma ação qualquer, é preciso que se saiba o que se quer. De uma forma análoga, a comunicação por meio da linguagem só parece possível quando se conhece que há uma intencionalidade própria e, de forma mais aprimorada, a linguagem torna-se mais eficaz quando se conhecem as intenções do outro (Carpenter e cols., 1998; Tomasello, 2005).

Certamente, avanços biológicos e cognitivos ocorrem, antes que a criança possa alcançar plenamente o que se convencionou chamar Teoria da Mente, ou seja, o conjunto de habilidades que permitem o reconhecimento de que o interlocutor é um agente comunicativo dotado de desejos, crenças e intenções (Carpenter e cols., 1998; Tomasello, 2005). Durante esse desenvolvimento, a comunicação não verbal anteriormente desenvolvida por meio de expressões faciais e corporais, gestos e sons dá lugar à comunicação verbal ou coexiste com ela. A criança aprende que os sons, as palavras e os símbolos possuem significados próprios e passa a operar com representações. Futuramente, a capacidade simbólica e representacional fundará as bases para uma ação cada vez mais reflexiva e mais consciente, chegando à capacidade metarrepresentacional e metacognitiva.

\section{Considerações finais}

As FEs compreendem um sistema complexo de funções cognitivas relacionadas que viabilizam um comportamento sofisticado, apropriado ao meio, envolvendo atenção, memória, planejamento, raciocínio, tomada de decisão, controle e monitoramento de ações, entre outras. O processo por meio do qual esse sistema emerge, desde os primórdios do desenvolvimento, e se aprimora, ao longo do tempo, requer o reconhecimento dos diversos processos fisiológicos e cognitivos.

Embora os vários modelos explicativos das FEs já tenham elucidado, em parte, as funções e sistemas envolvidos nesse processamento, procurou-se mostrar que a relação da intencionalidade com a linguagem e com as FEs ainda não está clara. Acredita-se que a intencionalidade seja um pré-requisito para o desenvolvimento da linguagem (Carpenter e cols., 1998; Tomasello, 2005) e também para o desenvolvimento das funções executivas. Possivelmente estudos empíricos sejam capazes de estabelecer a relação existente entre funções executivas, linguagem e intencionalidade.

Modelos futuros sobre funções executivas, fundamentados nos estudos experimentais já disponíveis e em fase de construção, poderiam considerar a importância da linguagem e da intencionalidade (Carpenter e cols., 1998; Tomasello, 2005) nesses processos, buscando-se restabelecer as relações anteriormente já apontadas por Luria $(1966,1970)$ e Vygotsky (1998a, 1998b).

Levantando-se a hipótese de que a intencionalidade é um componente que interrelaciona as FEs com a linguagem, estudos realizados cedo no ciclo vital podem vir a esclarecer se e em que ponto, durante o desenvolvimento típico, esses processos se independentizam. Essa perspectiva pode diminuir a dificuldade em se estabelecer a emergência das FEs, especialmente do componente da ação dirigida a objetivos. Também poderá favorecer um novo paradigma de avaliação, e em casos de transtornos invasivos do desenvolvimento, especialmente do espectro autista que tende a afetar habilidades comunicativas, bem como o TDAH, em que uma das manifestações possíveis é sabidamente a de disfunções executivas.

\section{Referências}

Baddeley, A. D. (2007). Working memory, thought and action. Oxford, United Kingdom: Oxford University Press.

Baddeley, A. D., \& Hitch, G. J. (1974). Working memory. In G. Bower (Ed.), The psychology of learning and motivation (pp. 47-90). San Diego, CA: Academic Press.

Baron-Cohen, S., Leslie, A. M., \& Frith, U. (1985). Does the autistic child have a theory of mind? Cognition, 21(2), 37-46.

Bechara, A., Damasio, A. R., Damasio, H., \& Anderson, S. W. (1994). Insensitivity to future consequences following damage to human prefrontal cortex. Cognition, 50(1-3), 7-15.

Bosa, C.A. (2001). As relações entre autismo, comportamento social e função executiva. Psicologia: Reflexão e Crítica, 14(2), 281-287.

Caramazza, A., \& McCloskey, M. (1988). The case for single patients studies. Cognitive Neuropsychology, 5(5), 517-528.

Carpenter, M., Nagell, K., \& Tomasello, M. (1998). Social cognition, joint attention and communicative competence from 9 to 15 months of age. Monographs of the Society for Research in Child Development, 63(4), 1-33.

Chomsky, N. (1957). Syntactic structures. Berlin: The Hague.

Chomsky, N., Belletti, A., \& Rizzi, L. (2002). Nature and language, with and essay on The secular priesthood and the perils of democracy. Cambridge, United Kingdom: Cambridge University Press.

Cummings, J. L. (1995). Anatomic and behavioral aspects of frontal-subcortical circuits. Annals of the New York Academy of Sciences, 769, 1-13.

Diamond, A. (1998). Evidence for the importance of dopamine for prefrontal cortex functions early in life. In A. C. Roberts, T. W. Robbins, \& L. Weiskrantz (Eds.), The prefrontal cortex. Executive and cognitive functions (pp. 144-164). Oxford, United Kingdom: Oxford University Press. 
Filley, C. M., Young, D. A., Reardon, M. S., \& Wilkening, G. N. (1999). Frontal lobes lesions and executive dysfunction in children. Neuropsychiatry, Neuropsychology and Behavioral Neurology, 12(3), 156-160.

Foster, J. K., Black, S. E., Buck, B. H., \& Bronskill, M. J. (1997). Ageing and executive functions: A neuroimaging perspective. In P. Rabbitt (Ed.), Methodology of frontal and executive function (pp. 177-190). Hove, United Kingdom: Psychology Press.

Frawley, W.(2000). Vygotskyea ciência cognitiva: Linguagem e integração das mentes social e computacional. Porto Alegre: Artes Médicas.

Fuster, J. M. (1997). The prefrontal cortex. Anatomy, physiology, and neuropsychology of the frontal lobe (3rd ed.). Philadelphia, PA: Lippincott-Raven.

Fuster, J. M. (2002). Frontal lobe and cognitive development. Journal of Neurocytology, 31(3-5), 373-385.

Fuster, J. M. (2004). Upper processing stages of the perception-action cycle. Trends in Cognitive Sciences, 8(4), 143-145.

Grafman, J. (1995). Similarities and distinctions among current models of prefrontal cortical functions. Annals of the New York Academy of Science, 769, 337-368.

Huttenlocher, P. R. (1990). Morphometric study of human cerebral cortex development. Neuropsychologia, 28(6), 517-527.

Jurado, M. B., \& Rosselli, M. (2007). The elusive nature of executive functions: Areview of four current understanding. Neuropsychological Review, 17(3), 213-233.

Luria, A. R. (1966). Higher cortical functions in man. New York: Basic Books.

Luria, A. R. (1970). The functional organization of the brain. Scientific American, 222(3), 66-78.

Luria, A. R. (1973a). The working brain. An introduction to neuropsychology. New York: Basic Books.

Luria, A. R. (1973b). The frontal lobes and the regulation of the behaviour. In K. H. Pribram \& A. R. Luria (Eds.), Psychophysiology of the frontal lobes (pp. 3-26). New York: Academic Press.

Malloy-Diniz, L. F., Cardoso-Martins, C., Carneiro, K. C., Cerqueira, M. M. M., Ferreira, A. P. A., Aguiar, M. J. B., \& Starling, A. L. (2004). Funções executivas em crianças fenilcetonúricas: Variações em relação ao nível de Fenilalanina. Arquivos de Neuropsiquiatria, 62(2b), 473-479.

Nydén, A., Gillberg, C., Hyelmquist, E., \& Heiman, M. (1999). Executive function/attention deficits in boys with Asperger syndrome, attention disorder and reading/ writing disorder. Autism, 3(3), 213-228.

Perner, J., Lang, B., \& Kloo, D. (2002). Theory of mind and self-control: More than a problem of inhibition. Child Development, 73(3), 752-767.

Piaget, J. (2003). Seis estudos de psicologia (24a ed., M. A. M. D’Amorim \& P. S. L. Silva, Trads.). Rio de Janeiro: Forense Universitária. (Original publicado em 1964)
Piaget, J., \& Inhelder, B. (1975). A gênese das estruturas lógicas elementares (A. Cabral, Trad.). Rio de Janeiro: Jorge Zahar. (Original publicado em 1959)

Pinker, S. (1997). Words and rules in the human brain. Nature, 387(6633), 547-548.

Searle, J. (1983). Intentionality: An essay in the philosophy of mind. Cambridge, United Kingdom: Cambridge University Press.

Shonen, S., Van Hout, A., Mancini, J., \& Livet, M. O. (1998). Neuropsychologie et développement Cognitif. In X. Seron \& M. Jeannerod (Eds.), Neuropsychologie humaine (pp. 487-527). Sprimont, Belgique: Mardaga.

Skinner, B. F. (1957). Verbal behavior. New York: Appleton Century Crofts.

Stuss, D. T., \& Benson, D. F. (1984). Neuropsychological studies of the frontal lobes. Psychological Bulletin, 95(1), 3-28.

Stuss, D. T., \& Benson, D. F. (1986). The frontal lobes. New York: Raven Press.

Stuss, D. T., \& Levine, B. (2002). Adult clinical neuropsychology: Lessons from studies of the frontal lobes. Annual Review of Psychology, 53, 401-433.

Tomasello, M. (2005). Constructing a language: A Usagebased theory of language acquisition. Harvard, MA: Harvard University Press.

Vygotsky, L. S. (1998a). A formação social da mente. São Paulo: Martins Fontes.

Vygotsky, L. S. (1998b). Pensamento e linguagem. São Paulo: Martins Fontes.

Zelazo, P. D., Craik, F. I. M., \& Booth, L. (2004). Executive function across the life span. Acta Psychologica, 115(2-3), 167-183.

Lauren Tonietto é Doutora em Psicologia pela Universidade Federal do Rio Grande do Sul.

Gabriela Peretti Wagner é Doutora em Psicologia pela Universidade Federal do Rio Grande do Sul.

Clarissa Marceli Trentini é Professora dos cursos de Graduação e Pós-graduação em Psicologia do Instituto de Psicologia da Universidade Federal do Rio Grande do Sul.

Tania Mara Sperb é Professora colaboradora do Programa de Pós-graduação em Psicologia da Universidade Federal do Rio Grande do Sul.

Maria Alice de Mattos Pimenta Parente é Professora colaboradora do Programa de Pós-graduação em Psicologia da Universidade Federal do Rio Grande do Sul.

Recebido: 17/05/2009

$1^{a}$ revisão: $26 / 04 / 2010$

Aceite final: 04/09/2010 